\title{
Evaluación de títulos de anticuerpos contra la enfermedad infecciosa bursal en gallinas de traspatio
}

\author{
Duarte, A. ${ }^{1}$; Méndez, G. ${ }^{1}$; Gómez, H. ${ }^{1}$; Alvarenga, D. ${ }^{1}$; Castro, L. ${ }^{1,2}$ \\ ${ }^{1}$ Facultad Ciencias Agropecuarias y Ambientales, Universidad Nacional \\ de Canindeyú, Curuguaty, Paraguay. ${ }^{2}$ Facultad Cs. Veterinarias, Univ. \\ Nac. Asunción, San Lorenzo, Paraguay. E-mail: lizaurora@gmail.com
}

\begin{abstract}
Resumen
Duarte, A.; Méndez, G.; Gómez, H.; Alvarenga, D.; Castro, L.: Evaluación de títulos de anticuerpos contra la enfermedad infecciosa bursal en gallinas de traspatio. Rev. Vet. 30: 2, $X X-X X$, 2019. La enfermedad infecciosa bursal (EIB), representa una de las principales patologías que afecta a las poblaciones avícolas de traspatio. La infección es producida por un virus altamente contagioso que ocasiona importantes pérdidas económicas, principalmente asociada con inmunosupresión. El objetivo de este trabajo fue evaluar niveles de anticuerpos en gallinas de traspatio de la ciudad de Curuguaty, Paraguay. Se obtuvieron muestras de sangre de 16 aves aparentemente sanas, sin distinción de sexo ni edad, que no habían recibido vacunación. La técnica serológica utilizada fue ELISA de tipo indirecto. Del total de muestras analizadas un 37,5\% presentó títulos de anticuerpos contra la EIB. Considerando el sexo, machos y hembras revelaron $100 \%$ y 16,3\% de positividad, respectivamente. La mayor cantidad de casos se reportó en aves jóvenes de 3 a 6 meses de edad. Los resultados obtenidos demuestran la existencia de cepas circulantes del virus de la EIB a campo, por lo cual es necesaria la implementación de programas de control capaces de erradicar el agente causal.
\end{abstract}

Palabras clave: gallina, enfermedad infecciosa bursal, anticuerpos, ELISA, traspatio, Paraguay.

Recibido: setiembre 2018 / Aceptado: diciembre 2018

Duarte, A.; Méndez, G.; Gómez, H.; Alvarenga, D.; Castro, L.: Evaluation of antibody titers against infectious bursal disease in backyard chickens. Rev. Vet. 30: 2, XX$X X, 2019$. Infectious bursal disease (IBD), represents one of the main pathologies that affects backyard poultry populations. Infection is produced by a highly contagious virus that causes significant economic losses, mainly associated with immuno-suppression. The objective of this work was to evaluate antibody levels in backyard hens of Curuguaty City, Paraguay. Blood samples were obtained from 16 healthy birds, without distinction of sex, age and that did not received vaccination. The serological technique was indirect ELISA. Of the total samples analyzed, 37.5\% had antibody titers against IBD. Considering the sex, $100 \%$ and $16.3 \%$ were reported as positives in males and females, respectively. The largest number of cases was reported in young birds from 3 to 6 months of age. Results show that there are circulating strains of IBD virus in the field. The necessity of the implementation of adequate control programs in order to eradicate the causal agent, is emphasized. 
Palabras clave: backyard chicken, infectious bursal disease, antibody titers, ELISA, backyard, Paraguay.

\section{INTRODUCCIÓN}

En Paraguay, la producción de carne y huevos de aves contribuye a lograr una dieta balanceada, principalmente para los niños ${ }^{1}$. No obstante, la presencia de enfermedades infecciosas aviares menoscaba tal cometido, ocasionando pérdidas económicas por alteraciones en la producción de huevos, bajas tasas de crecimiento y muerte de animales.

Una de las principales patologías que afecta mundialmente a las aves de corral es la enfermedad infecciosa bursal (EIB) ${ }^{4}$. El virus causante pertenece al género Avibirnavirus, familia Birnaviridae, el cual presenta una cápside icosaédrica de una sola capa con un diámetro entre 55 y $60 \mathrm{~nm}$. Tal estructura, relativamente simple, le confiere al virus una alta resistencia en el medio ambiente, representando un problema clave en el control de esta enfermedad ${ }^{8}$.

La afección ocasiona rápida y alta mortalidad, principalmente en aves jóvenes, provocando la destrucción de órganos linfoides, particularmente la bolsa de Fabricio, donde ocurre la maduración y diferenciación de los linfocitos $\mathrm{B}^{4}$.

En Paraguay, el departamento Canindeyú posee una existencia de alrededor de 460.000 aves, siendo la ciudad de Curuguaty la de mayor densidad, con un total de 160.000 ejemplares ${ }^{3}$. La explotación de este tipo de aves asume importancia en la producción familiar a nivel rural por generar ingresos económicos y constituir una fuente proteica de alto valor biológico.

Dada la ausencia de datos publicados sobre la existencia de EIB en dicha zona, el objetivo de este trabajo fue evaluar los títulos de anticuerpos contra tal enfermedad en gallinas de traspatio.

\section{MATERIAL Y MÉTODOS}

Fueron seleccionadas al azar 16 gallinas criollas sin distinción de sexo ni edad, aparentemente sanas, exentas de vacunaciones, criadas en traspatios de la ciudad de Curuguaty. Las muestras de sangre $(1 \mathrm{ml} /$ ave $)$ se obtuvieron de la vena braquial utilizando jeringas de $5 \mathrm{ml}$ con aguja 23G x 1". Inmediatamente fueron depositadas en tubos sin anticoagulante y colocadas de forma horizontal a temperatura ambiente.

El suero sanguíneo se conservó en microtubos de $1,5 \mathrm{ml}$ que se mantuvieron a $-20^{\circ} \mathrm{C}$ hasta su procesamiento en el laboratorio. El análisis serológico se realizó utilizando ELISA de tipo indirecto, siguiendo las recomendaciones del fabricante (Idexx Laboratories Inc Westbrook, Maine, USA) en el Laboratorio Avícola de Paraguay.

Los datos obtenidos fueron transferidos a una hoja de cálculo de Microsoft Excel (Microsoft Corporation, Redmond, WA, USA) y los resultados se analizaron en porcentajes.

\section{RESULTADOS Y DISCUSIÓN}

Del total de muestras estudiadas, el 37,5\% presentó títulos de anticuerpos contra la enfermedad infecciosa bursal. Teniendo en cuenta los sexos, las muestras positivas fueron del $100 \%$ en los machos y del $16,3 \%$ en las hembras. 
Los valores encontrados en este trabajo fueron inferiores a los reportados en gallinas de Kenya ${ }^{2}$ y en aves de traspatio de Etiopía ${ }^{5,6}$.

En cambio, nuestros resultados fueron similares a los hallados en Tanzania ${ }^{7}$, donde se registraron tasas de prevalencia superiores en machos con relación a las hembras. La gran diferencia entre ambos sexos hallada en este estudio, podría estar relacionada con la edad, teniendo en cuenta que la totalidad de los machos muestreados, tenían de 6 a 9 meses de vida.

El mayor número de casos positivos se observó en aves jóvenes (83,3\%) con edades comprendidas entre 6 a 9 meses, y en menor número en aves de 12 a 24 meses. La aparición de la enfermedad podría estar relacionada con el desarrollo de la bolsa de Fabricio, aumentando la susceptibilidad en animales entre 3 y 6 meses de edad.

Las diferencias reportadas podrían deberse a variables como la técnica de diagnóstico utilizada, las condiciones medioambientales y las líneas, razas y condiciones de manejo empleadas. Los resultados obtenidos evidencian la circulación de cepas del virus, por lo cual resulta necesario implementar adecuados programas de vacunación para disminuir su diseminación entre las poblaciones avícolas.

\section{REFERENCIAS}

1. Baksi S, Rao N, Khan M. 2018. Evaluation of specific antibody response in backyard chickens to infectious bursal disease live vaccine. PSM Vet Res 3: 1-5.

2. Dirección de Censos y Estadísticas Agropecuarias (DCEA). 2008. Censo Agropecuario Nacional. (San Lorenzo, Paraguay), 5: 90.

3. Ingrao F, Rauw F, Lambrecht B, Berg T. 2013. Infectious bursal disease: a complex host-pathogen interaction. Dev Comp Immunol 41: 429-438.

4. Swai E, Kessy M, Sanka P, Mtui P. 2011. A serological survey for infectious bursal disease virus antibodies in free-range village chickens in northern Tanzania. Jl S Afr Vet Ass 82: 32-35.

5. Tadelle D, Million T, Alemu Y, Peters K. 2003. Village chicken production systems in Ethiopia: 2. Use patterns and performance valuation and chicken products and socio-economic functions of chicken. Liv Res Rural Develop 15: 1. On line: http://www.lrrd.org/lrrd15/1/tadeb151.htm

6. Tadesse B, Jenbere S. 2014. Sero-prevalence of infectious bursal disease in backyard chickens at selected woredas of Eastern Ethiopia. J Biol Agr Healt 4: 70-75.

7. Wahome $\mathbf{N}$ et al. 2017. Ocurrence of antibodies to infectious bursal disease virus in non-vaccinated indigenous chicken, ducks and turkeys in Kenya. Inter J Vet Sci 6: 159-162.

8. Zegeye S, Tsegaye Y, Haftay A, Awol N. 2015. Sero-prevalence of infectious bursal disease in backyard around Mekelle, Northern Ethiopia. Afr J Biotechnol 14: 434437. 